\title{
ANAESTHETIC MANAGEMENT OF BILATERAL PHEOCHROMOCYTOMA
}

\author{
Joginder Pal Attri, Veena Chatrath, Ranjana Khetarpal, Gurmeet Kaur Anand, Anju Bala
}
1. Associate Professor, Department of Anaesthesia. Govt. Medical College, Amritsar
2. Professor \& Head, Department of Anaesthesia. Govt. Medical College, Amritsar
3. Assistant Professor, Department of Anaesthesia. Govt. Medical College, Amritsar
4. Senior Resident, Department of Anaesthesia. Govt. Medical College, Amritsar
5. Senior Resident, Department of Anaesthesia. Govt. Medical College, Amritsar

\section{CORRESPONDING AUTHOR}

Dr. Joginder Pal Attri, H. No C-13, Medical College Campus, Guru Nanak Dev Hospital, Circular Road, Amritsar. (Punjab)-143001

E-mail: jpattri12@yahoo.co.in, Ph: 00919501025275.

ABSTRACT: A 27 year old female patient with bilateral pheochromocytoma presented with hypertension. Confirmation of diagnosis was done by CT scan and raised 24 hour urinary vanillylmandelic acid levels. Preoperative BP was controlled with prazosin, labetolol, indapamide and clonidine. The anaesthetic technique used was general anaesthesia with epidural analgesia.

KEY WORDS : Pheochromocytoma, hypertension, anaesthetic management

INTRODUCTION: Pheochromocytoma is a catecholamine secreting tumour of chromaffin tissue which can produce excessive amounts of catecholamines. These tumours are most often found in adrenal glands but can also occur in chromaffin cells in or about sympathetic ganglia. These tumours are not common, occurring in $0.1 \%$ of hypertensive population only. ${ }^{1}$ Pheochromocytoma typically occurs in a patient who is 30-50 years of age. ${ }^{2}$ A "rule of 10 " has been applied to these tumours- $10 \%$ are bilateral, $10 \%$ are malignant and $10 \%$ are extraadrenal. ${ }^{1,5}$

CASE REPORT: A 27 year old, $50 \mathrm{~kg}$, female patient presented with confirmed diagnosis of bilateral adrenal pheochromocytoma on CT scan for removal of tumour. On pre-operative check up, her BP was 240/126 mmHg. 24 hour urinary vanillylmandelic acid level was 47.70mg. Plain X-ray KUB showed inferior displacement of right kidney. On echocardiography, LVEF was 60\% at rest with normal global and segmental wall motion. There were occasional premature atrial contractions on E.C.G. Serum cortisol level was $26.09 \mu \mathrm{g} / \mathrm{dL}$. FBS was $98.0 \mathrm{mg} / \mathrm{dL}$. Other investigations like haemoglobin, renal profile, serum electrolytes, serum calcium, thyroid profile, liver function tests and P.T.I. were normal. Her Blood pressure (BP) was controlled with prazosin $10 \mathrm{mg}$ OD, labetolol $100 \mathrm{mg} \mathrm{BD}$, indapamide $1.25 \mathrm{mg}$ OD, clonazepam $1 \mathrm{mg}$ OD and clonidine $250 \mu \mathrm{g}$ OD. She was taken up for surgery when her BP was $140 / 90 \mathrm{mmHg}$ with no signs of postural hypotension. Her haematocrit was $31.7 \%$.

Anaesthetic management

Morning dose of oral antihypertensives and clonazepam were given. Injection butorphanol $1 \mathrm{mg}$ I.V. was given as premedication. Preanaesthetic BP was 140/86 mmHg and heart rate was $74 / \mathrm{min}$. IV line was maintained with $18 \mathrm{G}$ cannula. Monitors were attached for continuous monitoring of NIBP, IBP, CVP, ECG, $\mathrm{SpO}_{2}$ and temperature. Radial artery cannulation 
and right subclavian central line insertion was done. Initial CVP was $8 \mathrm{~cm} \mathrm{H}_{2} \mathrm{O}$. 18G epidural catheter was inserted in $\mathrm{L} 2 / 3$ inter-vertebral space and after a test dose of $3 \mathrm{ml}$ injection lignocaine $2 \%$ with $1: 200000$ adrenaline, $10 \mathrm{ml}$ of $0.5 \%$ plain bupivacaine with $50 \mu$ g clonidine was given. Urinary catheterisation was done. After preoxygenation for three minutes, patient was induced with propofol 100mg, vecuronium $5 \mathrm{mg}, \mathrm{N}_{2} \mathrm{O}: \mathrm{O}_{2}$ (50:50) and isoflurane $1 \%$. 75mg xylocard was given one minute before laryngoscopy to avoid stress response and intubation was done. $\mathrm{EtCO}_{2}$ monitoring was done throughout surgery. Maintenance of anaesthesia was done with $\mathrm{O}_{2}: \mathrm{N}_{2} \mathrm{O}$, isoflurane, vecuronium and positive pressure ventilation. Intra-operative BP surge of $>200 / 110 \mathrm{mmHg}$ was controlled by $0.01 \%$ infusion of sodium nitroprusside (SNP) and heart rate more than 100/min by intermittent bolus of metoprolol $2 \mathrm{mg}$. After three hours of surgery, $10 \mathrm{ml}$ of $0.5 \%$ plain bupivacaine was given through epidural catheter. After the removal of tumour, there was precipitous fall of $\mathrm{BP}$ and the same was restored by rapid infusion of Ringer lactate 2.5L, Haemaccel $500 \mathrm{ml}, 2$ units of blood and noradrenaline infusion. Injection hydrocortisone $200 \mathrm{mg}$ was given after removal of the tumour. Urine output was maintained throughout the procedure. At the conclusion of the surgery, patient was reversed with neostigmine and glycopyrrolate and extubated. Patient was fully awake and maintained her vitals with support of noradrenaline. Post-operative analgesia continued through epidural catheter. Patient was shifted to ICU for continuous monitoring of vitals. Post-operative steroid cover was continued. Patient remained stable in ICU and in ward. She was discharged on $15^{\text {th }}$ day with stable BP.

DISCUSSION: Primary pre-operative goal should be good pharmacological control of adverse effects of circulatory catecholamines and restoration of blood volume by $\alpha$ - adrenoreceptor blockade. Several authors suggest the use of calcium channel blockers (verapamil 120-240 mg every day, nifedipine $30-90 \mathrm{mg}$, diltiazem $180 \mathrm{mg}$ daily) to prepare the patient in preoperative period. These agents do not cause postoperative hypotension and can control the rhythm and heart rate. 7,8 Our patient was given prazosin, a selective $\alpha$-blocker that causes less tachycardia and postural hypotension than other $\alpha$-adrenoreceptor blockers. ${ }^{4}$ Labetalol was added later on to control tachycardia. Another approach involves the administration of metyrosine (alphamethyl-para-tyrosine), which inhibits catecholamine synthesis. In one report, the patients given metyrosine had a smoother perioperative course than those given phenoxybenzamine alone. ${ }^{9}$

The main aim of anaesthetic management is to provide optimal surgical conditions and suppress the response of endotracheal intubation, surgical stimulation, tumour handling and devascularisation. Combined regional and general anaesthetic technique is preferred, so we used epidural anaesthesia with general anaesthesia to expand the vascular bed and provide preemptive and post-operative analgesia ${ }^{4}$. It is most appropriate to administer an anxiolytic sedative preferably a benzodiazepine to decrease catecholamine release. ${ }^{3}$ Our patient was already taking clonazepam so we gave $1 \mathrm{mg}$ IV butorphanol as premedication. Monitoring in our case was performed as per recommendation. ${ }^{1}$ Drugs causing histamine release were avoided. The anaesthetic agents preferred were propofol, isoflurane and nitrous oxide. Isoflurane was used in our patient because it does not sensitise the heart to catecholamines and decreases the peripheral resistance too. ${ }^{1}$ Vecuronium was preferred as a relaxant due to it's lack of cardiovascular effects and histamine release. ${ }^{1}$ Lignocaine $1.5 \mathrm{mg} / \mathrm{kg}$ IV was given 1 minute before laryngoscopy to attenuate the stress response. ${ }^{2}$ To control BP and tachycardia, we used continuous IV infusion of SNP and metoprolol IV boluses. There are recent reports of usage of I/V infusions of dexmedetomidine and magnesium sulphate in perioperative management of 
pheochromocytomas. ${ }^{6}$ Steroid cover is mandatory for patients undergoing bilateral adrenalectomy. We also used hydrocortisone in intra-operative and post-operative period.

In conclusion, the proper anaesthetic management of pheochromocytoma is a truly rewarding challenge. Mortality has been reduced in recent years due to better knowledge of these bizarre tumours, particularly the chronic hypovolemia produced, and more adequate pretreatment regimens, better intra and post- operative management.

\section{REFERENCES:}

1. Brown R. Brunell Jr. Anaesthesia for Pheochromocytoma. In: Robert C Prys and Brown R. Brunell Jr. Editors International practice of anaesthesia.

2. Stoelting RK, Dierdosrf SF. Endocrine diseases. Anaesthesia and Co-existing diseases 2002; 430-434.

3. Published - butterworth-Heinemann 1996; 1/83/1-7 G.Singh, P.Kam. An overview of anaesthetic issues in Pheochromocytoma.Ann acad Singapore 1998;27:843-8.

4. Roberts C. Prys. Pheochromocytoma- Recent progress in it's management. Br J Anaesth 2000; 85(1): 44-57.

5. Joet T. Alder, Goswin Y et al. Phaeocchromocytoma: Current approaches and future directions. The Oncologist 2008; 13:779-793.

6. Bryskin R, Weldon BC. Dexmedetomidine and magnesium sulfate in the perioperative management of a child undergoing laparoscopic resection of bilateral pheochromocytomas. J Clin Anesth. 2010 Mar;22(2):126-9.

7. Domi R, Laho H. Management of pheochromocytoma: Old ideas and new drugs. Niger J Clin Pract 2012;15:253-7.

8. Lebuffe G, Dosseh ED, Tek G, Tytgat H, Moreno S, Tavernier B, et al. The effect of calcium channel blockers on outcome following the surgical treatment of pheochromocytomas and paragangliomas. Anaesthesia 2005;60:439-44.

9. Steinsapir J, Carr AA, Prisant LM, Bransome ED Jr. Metyrosine and pheochromocytoma. Arch Intern Med 1997; 157:901. 